$\longrightarrow \square$

The method of estimation and forecasting in intelligent decision support systems is developed. The essence of the proposed method is the ability to analyze the current state of the object under analysis and the possibility of short-term forecasting of the object state. The possibility of objective and complete analysis is achieved through the use of improved fuzzy temporal models of the object state, an improved procedure for forecasting the object state and an improved procedure for training evolving artificial neural networks. The concepts of a fuzzy cognitive model, in contrast to the known fuzzy cognitive models, are connected by subsets of fuzzy influence degrees, arranged in chronological order, taking into account the time lags of the corresponding components of the multidimensional time series. This method is based on fuzzy temporal models and evolving artificial neural networks. The peculiarity of this method is the ability to take into account the type of a priori uncertainty about the state of the analyzed object (full awareness of the object state, partial awareness of the object state and complete uncertainty about the object state). The ability to clarify information about the state of the monitored object is achieved through the use of an advanced training procedure. It consists in training the synaptic weights of the artificial neural network, the type and parameters of the membership function, as well as the architecture of individual elements and the architecture of the artificial neural network as a whole. The object state forecasting procedure allows conducting multidimensional analysis, consideration and indirect influence of all components of a multidimensional time series with different time shifts relative to each other under uncertainty

Keywords: decision support systems, artificial neural networks, state forecasting, training

\section{DEVELOPMENT OF ESTIMATION AND FORECASTING METHOD IN INTELLIGENT DECISION SUPPORT SYSTEMS}

I gor Romanenko Doctor of Technical Sciences, Professor, Leading Researcher Scientific Research Department*

Andrii Golovanov $\mathrm{PhD}$, Associate Professor, Head of Department Department of Operational Art**

Vitalii Khoma

$\mathrm{PhD}$, Associate Professor, Head Scientific and Methodological Center of Scientific, Scientific and Technical Activities Organization**

Andri i Shysatskyi $\mathrm{PhD}$, Senior Researcher Research Department of Electronic Warfare Development* E-mail: ierikon13@gmail.com

Yevhen Dem chenko $\mathrm{PhD}$, Head of Research Department Research Department of Scientific and Methodological Support for the Development and Implementation of Programs for the Development of Weapons And Military Equipment and the State Defense Order Research Department*

Lyubov Shabanova-Kushnarenko $\mathrm{PhD}$, Associate Professor Department of Intelligent Computer Systems National Technical University «Kharkiv Polytechnic Institute» Kyrpychova str., 2, Kharkiv, Ukraine, 61002

Tetiana Ivakhnenko $\mathrm{PhD}$, Leading Researcher Research Department of Development of Anti-Aircraft Missile Systems and Complexes* O leksandr Prokopenko Adjunct Center of Military and Strategic Studies** Oleh Havaliukh $\mathrm{PhD}$

Department of Weapons Naval Institute of the National University «Odessa Maritime Academy» Didrichsona str., 8, Odessa, Ukraine, 65029

D m i tro $\mathbf{S t u p a k}$

$\mathrm{PhD}$, Associate Professor Department of Electrical Engineering and Electronics Zhytomyr Military Institute named after S. P. Koroliov Myru ave., 22, Zhytomyr, Ukraine, 10004

*Central Scientifically-Research Institute of Arming and Military Equipment of the Armed Forces of Ukraine Povitrofloski ave., 28, Kyiv, Ukraine, 03049 **National Defence University of Ukraine named after Ivan Cherniakhovskyi Povitroflotskyi ave., 28, Kyiv, Ukraine, 03049
Received date 15.02.2021 Accepted date 14.04.2021 Published date 30.04.2021
How to Cite: Romanenko, I., Golovanov, A., Khoma, V., Shyshatskyi,A., Demchenko, Y., Shabanova-Kushnarenko, L., Ivakhnenko, T., Prokopenko, O., Havaliukh, O., Stupak, D. (2021). Development of estimation and forecasting method in intelligent decision support systems. Eastern-European Journal of Enterprise Technologies, 2 (4 (110)), 38-47. doi: https:// doi.org/10.15587/1729-4061.2021.229160

\section{Introduction}

Decision support systems (DSS) are actively used in all spheres of human life. They gain popularity in processing large amounts of data, process forecasting, providing information support for decision-makers.

The basis of existing DSS are artificial intelligence methods, which provide collection, processing, generalization 
of information about the state of objects (processes) and forecasting of their future state.

The creation of intelligent DSS has become a natural continuation of the widespread use of classical DSS. Intelligent DSS provide information support for all production processes and services of enterprises (organizations, institutions). Intelligent DSS allow for designing, manufacturing and selling products, financial and economic analysis, planning, personnel management, marketing, support for the creation (operation, repair) of products and long-term planning. Also, intelligent DSS are widely used to solve specific military problems, for example [1,2]:

- planning the deployment and operation of communication and data transmission systems;

- automation of troops and weapons management;

- planning of combat training of units (subdivisions) and quality control of learning material assimilation;

- collection, processing and generalization of intelligence information about the state of intelligence objects, etc.

The structure of intelligent DSS can be conventionally divided into 4 major layers:

- interface layer (interactivity and visualization);

- modeling layer (statistical models and machine learning; numerical models; game theory models, etc.);

- data processing layer (organization of data flow, work with databases and expert evaluation);

- data collection layer (web scanning, sensors and programming interface).

Analysis of the experience of creating intelligent DSS shows that the most promising is an information technology based on neural network modeling [1-8], in particular on the application of an evolutionary approach to the construction of artificial neural networks (ANN) [4, 5].

Applying the evolutionary approach to the construction of neural networks in comparison with traditional approaches gives the following advantages:

- quick adaptability to the subject area, which almost without any changes makes it possible to form a structure of ANN, which corresponds to this process;

- quick learning ability; based on models of neurons with the corresponding thresholds, weights and transfer functions to construct the trained ANN already in the first approximation;

- operability under uncertainty, nonlinearity, stochasticity and randomness, various disturbances and interference;

- both universal approximating properties and fuzzy inference capabilities.

Evolving ANN are widely used to solve various problems of data mining, planning, control, identification, emulation, forecasting, intelligent management, etc. on each layer of intelligent DSS.

Despite their successful use to solve a wide range of data mining problems, these systems have a number of disadvantages.

The most significant shortcomings are the following:

1. Complexity of choosing system architecture. As a rule, the model based on the principles of computational intelligence has a fixed architecture. In the context of ANN, this means that the neural network has a fixed number of neurons and connections. Therefore, adapting the system to new processing data that are different from the previous data may be problematic.

2. Batch training and training for several epochs require significant time resources. Such systems are not adapted to work online with a fairly high rate of new processing data.

3. Many of the existing computational intelligence systems can not determine evolving rules by which the system develops and can also present the results of their work in terms of natural language.

4. Problems with many indicators that have a complex structure of relationships and contradict each other.

5. Difficulty of taking into account the indirect influence of interdependent components under uncertainty.

6. Nonlinearity of interaction of objects and processes, non-stochastic uncertainty, partial inconsistency and significant interdependence of components.

These shortcomings can be eliminated by fuzzy cognitive maps. Fuzzy cognitive maps have proved themselves well in the problems of studying the structure of the modeled system and forecasting its behavior under various control influences and evolving ANN.

There is an urgent scientific problem of developing a method of estimation and forecasting in intelligent decision support systems using artificial neural networks and fuzzy cognitive models.

\section{Literature review and problem statement}

The work [9] presents the cognitive modeling algorithm. The main advantages of cognitive tools are determined. During the construction of the experimental model, the target factors of the cognitive map were determined, connectivity analysis was performed, and the process of perturbation propagation on the graph was studied. The proposed model is used to forecast economic activity and determine the expected values of parameters to be monitored for diagnosing trends in the development of an industrial enterprise. The disadvantages of this approach include the lack of consideration of the type of uncertainty about the state of the analyzed object.

The work [10] revealed the essence of cognitive modeling and scenario planning. The system of complementary principles of scenario construction and implementation is proposed, various approaches to scenario construction are identified, the procedure of scenario modeling on the basis of fuzzy cognitive maps is described. It is proposed to identify the concepts of the cognitive map based on the analysis of the internal and external environment of the organization, which will allow taking a systematic look at business conditions of an enterprise, predicting further development and making the right management decisions. The approach proposed by the authors does not take into account the type of uncertainty about the state of the analyzed object and does not take into account the delay in processing data about the object state.

The work [11] carried out the analysis of the main approaches to cognitive modeling. Cognitive analysis allows you to explore problems with fuzzy factors and relationships; take into account changes in the external environment and use objectively formed trends in the situation to your advantage. The need to develop a system of criteria for the formalization and automation of decision-making in problem areas is noted. It is also stated that the objectivity of processed information must be taken into account.

The work [12] described the agent-based approach used in a multi-agent information-analytical system and considered the problems of information decision support. The disadvantages of this approach include the limited representation of complex systems, namely, none of the agents has an idea of the entire system.

The work [13] presents the method of analysis of large data sets. This method focuses on finding hidden information 
in large amounts of data. The method includes the operations of generating analytical baselines, reducing variables, detecting sparse features and specifying rules. The disadvantages of this method include the inability to take into account various decision evaluation strategies.

The work [14] proposed the approach for estimating the cost of the client's life in the field of air transporttation. This approach firstly used a regression model followed by an indirect estimation model. At the final stage, the results are compared using both estimation models. The disadvantages of this approach include the inability to determine the adequacy of estimation.

The work [15] gives the approach to quantitative estimation for evaluating the optimum selection or/and testing of analytical methods. Objective criteria related to analytical performance, sustainability, environmental impact and economic costs are assessed by determining penalty points divided into five different blocks. For each block, the overall qualification is scaled from 0 to 4 and displayed on a regular hexagonal icon, which allows comparing analytical procedures. The disadvantages of this approach include the inability to increase the number of evaluated indicators.

The work [16] gives the mechanism of transformation of information models of construction objects to their equivalent structural models. This mechanism is designed to automate the necessary operations of conversion, modification and addition during such information exchange. The disadvantages of this approach include the inability to assess the adequacy and reliability of the information transformation process.

The work [17] carried out the development of an analytical web-platform for studying the geographical and temporal distribution of incidents. The web-platform contains several information panels with statistically significant results by territory. The web platform includes certain external sources of data on social and economic issues, which allow exploring the relationship between these factors and the distribution of incidents at different geographical levels. The disadvantages of this analytical platform include the inability to assess the adequacy and reliability of the information transformation process, as well as high computational complexity.

The work [18] developed the method of fuzzy hierarchical assessment of the library services quality. This method allows evaluating the libraries quality by a set of input parameters. The disadvantages of this method include the inability to assess the adequacy and reliability of the assessment.

The work [19] performed the analysis of 30 algorithms for processing large data sets. Their advantages and disadvantages are shown. It was found that the analysis of large data sets should be carried out in layers in real time and have the self-learning ability. The disadvantages of these methods include high computational complexity and the inability to verify the adequacy of the estimates.

The work [20] presented the approach to input data evaluation for decision support systems. The essence of the proposed approach is to cluster the basic set of input data, analyze them, and then train the system based on the analysis. The disadvantage of this approach is the gradual accumulation of evaluation and learning errors due to the inability to assess the adequacy of decisions.

The work [21] presented the approach to processing data from different sources of information. This approach allows processing data from various sources. The disadvantages of this approach include the low accuracy of the obtained estimate and the inability to verify the reliability of the obtained estimate.
The work [22] conducted a comparative analysis of existing decision support technologies, namely: hierarchy analysis method, neural networks, fuzzy set theory, genetic algorithms and neuro-fuzzy modeling. The advantages and disadvantages of these approaches are indicated. The spheres of their application are defined. It is shown that the hierarchy analysis method works well with complete initial information, but due to the need for experts to compare alternatives and choose evaluation criteria, it has a high share of subjectivity. The use of fuzzy set theory and neural networks is justified for forecasting problems under risk and uncertainty.

The work [23] considered the problematic aspects of information-analytical support of strategic decision-making in modern management. The role and place of the process of developing and making management decisions in strategic planning are specified. The existing approaches to accounting the regularities of the course and result of strategic processes are analyzed. In the analysis, it was found that the approaches and methods of modern model theory in control systems, which allow for linguistic approximation of mathematical models of cybernetic systems, are of special interest. This approximation ensures that the highest level of abstract system description is achieved, which allows identifying the most general concepts and exploring relationships between them. However, the results do not fully apply to organizational management systems. To solve strategic management problems, it is proposed to use fuzzy set and neural network theories.

The work [24] describes tools and methods for analyzing and processing information on the quantity and quality of personnel of the Ministry of Defense of the Czech Republic. The disadvantages of this approach include high computational complexity, the inability to assess the adequacy and reliability of decisions.

The work [25] described the approaches to processing constantly updated information circulating in social information communications, namely: active use of content monitoring, content analysis methods in this process. The disadvantages of these methods include high computational complexity.

The work [26] gives the system of hierarchical fuzzy estimation of the factors influencing the process of rice cultivation. The disadvantages of this method include the accumulation of evaluation errors due to the inability to assess the adequacy of evaluation.

The work [27] developed the method for determining and assessing the strategic economic potential of the theoretical and methodological foundations for forming and assessing the level of strategic economic potential of economic systems. This method is based on the use of the hierarchy analysis method. The disadvantages of this method include the dependence of the results on experts' competence and high computational complexity.

The work [28] developed the approach of determining the influence of the factors affecting the economic efficiency on the economy of integrated structures. This approach is based on the use of the expert evaluation method. The disadvantages of this approach include the dependence of the results on experts' competence and high computational complexity.

The work [29] developed a systematic approach to assessing the effectiveness of a strategic plan. The systematic approach is based on the use of the expert evaluation method. The disadvantages of this systematic approach include the dependence of the results on experts' competence and high computational complexity.

The analysis of works [9-29] showed that the vast majority use general scientific methods, such as systematic, 
comparative, structural and functional analysis, expert evaluation method, scenario analysis of socio-economic systems and theoretical information approach.

Common limitations of existing methods of multi-criteria fuzzy evaluation of alternatives are:

- complexity of forming a multilevel evaluation structure;

- lack of consideration of the compatibility of unevenly significant indicators;

- lack of the ability to jointly perform direct and inverse evaluation tasks with the support for choosing the best decisions.

To create decision support software, it is necessary to create fuzzy evaluation methods, which must meet the following requirements:

- the ability to form a generalized evaluation indicator and choose decisions based on sets of partial indicators, which change taking into account the complex multi-level evaluation structure;

- the ability to aggregate heterogeneous evaluation indicators (both quantitative and qualitative) and choose decisions that differ in measuring scales and ranges of values;

- taking into account the compatibility and different significance of partial indicators in the generalized assessment of decisions;

- consideration of different decision evaluation strategies;

- flexible adjustment (adaptation) of evaluation models while adding (excluding) indicators and changing their parameters (compatibility and significance of indicators);

- ensuring the implementation of the direct task of evaluating the generalized indicator on the basis of partial indicators; inverse evaluation task and joint execution of direct and inverse evaluation tasks within a single model.

For this purpose, it is proposed to develop a method of estimation and forecasting in intelligent decision support systems based on fuzzy temporal models and evolving artificial neural networks.

\section{The aim and objectives of the study}

The aim of the study is to develop a method of estimation and forecasting in intelligent decision support systems, which would allow analyzing and forecasting the objects state.

To achieve the aim, the following objectives were set:

- to conduct a formalized description of the problem of analyzing and forecasting the objects state in intelligent decision support systems;

- to formulate the presentation concept of the estimation and forecasting method in intelligent decision support systems;

- to determine the algorithm for implementing the method.

\section{Materials and methods of research}

The research used general provisions of the artificial intel- ligence theory to solve the problem of analyzing and forecasting the state of objects in intelligent decision support systems. Thus, the artificial intelligence theory is the basis of this research.

Fuzzy cognitive models were used to solve the problem of describing and forecasting the future state of dynamic objects. This allows describing how complex multi-level objects change over time. This study also uses the method of artificial neural network training developed in previous works, which allows for deep learning of artificial neural networks. The essence of deep learning is to learn the architecture, type and parameters of the membership function. The simulation was performed using MathCad 2014 software and an Intel Core i3 PC.

\section{Results of research on the development of the estimation and forecasting method in intelligent decision support systems}

5. 1. Formalized description of the problem of analyzing and forecasting the objects state in intelligent decision support systems

For analyzing and forecasting the state of the monitored object, it is proposed to apply a systematic approach.

Fig. 1 presents a block diagram of the control system for analyzing and forecasting the object state, which is divided into $[11,30]$ :

1) control subsystem (control subject, $S$ );

2) controlled subsystem (control object, $O$ );

3) object model (fuzzy cognitive model $Y$ ). The fuzzy cognitive model is used because the state of the analyzed object is usually characterized by numerical and qualitative indicators. This requires bringing them to a single unit of measurement.

Here are the explanations of the variables shown in Fig. 1:

$-W$ is the external information;

$-Q$ is the system resources required for analyzing and forecasting the object state;

$-H$ is the internal information needed to build fuzzy cognitive models (FCM);

$-H^{*}$ is the corrected error;

$-U$ is the control effect (management decision-making, control commands) (direct relationship);

- $Y_{\mathrm{CO}}$ is the initial information (actual data, parameters, indicators) that characterizes the state of the control object;

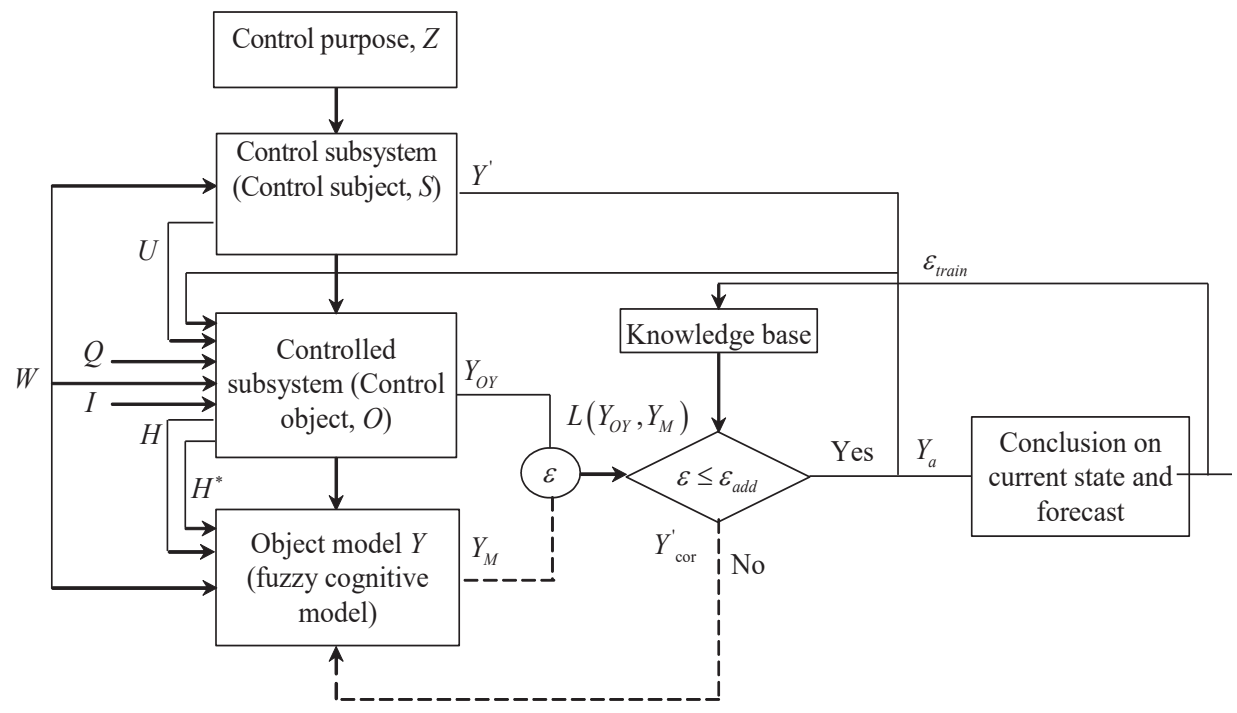

Fig. 1. Block diagram of the object state analysis and forecasting system 
$-Y_{m}$ is the output parameters of the model (desired, expected parameters);

$-\varepsilon$ is the error (inconsistency);

$-\varepsilon_{\text {add }}$ is the fixed setpoint;

$-L\left(Y_{\mathrm{CO}}, Y_{m}\right)$ is the check whether the data obtained on the basis of the model cor- respond to the real object for the description of which it is built;

$-Y^{\prime}$ is information about the object state (feedback);

$-Y_{a d j}^{\prime}$ is the model adjustment (adding new factors and relationships between them);

$-Y_{a}$ is the adequate model of the monitored object corresponding to its actual state;

$-\varepsilon_{\text {train }}$ is knowledge base updating.

The controlled subsystem $(O)$ is the control objects to which control effects are directed. The object model means the development and study of a fuzzy cognitive model for assessing the object state using the method of fuzzy cognitive modeling of the object state.

The control subsystem produces the control effect $U$ based on the control purpose and information received from the external environment $W$.

The controlled subsystem receives information $(Q, I, U)$, which forms the task of analyzing and forecasting the object state. Based on $W, Q, I$, fuzzy cognitive models are developed and investigated using the method of fuzzy cognitive modeling of the object analysis process, which allows investigating and analyzing possible scenarios of object development. System development scenarios are development scenarios of situations related to the nature of the monitored object actions.

If the obtained results (calculated values) $Y_{m}$ do not correspond to the actual results that characterize the state $Y_{\mathrm{CO}}$ (the condition $\varepsilon \leq \varepsilon_{\text {add }}$ is not fulfilled), the control subsystem makes adjustments to the FCM $\left(Y_{a d j}\right)$. If the condition $\varepsilon \leq \varepsilon_{\text {add }}$ is satisfied, then the FCM is adequate $Y_{a}$. The adequate FCM allows forecasting the behavior of the object.

To verify the adequacy of the model, a «historical method» is proposed, where the constructed FCM are applied to similar situations, if they occurred in the past and their dynamics are known. In this case, the FCM is effective (the results obtained coincide with the real course of events) and considered correct.

\section{2. Concept of presentation of the estimation and} forecasting method in intelligent decision support systems

Control is performed using the feedback $Y^{\prime}$. The control subsystem receives information from the controlled subsystem $Y^{\prime}$ and the external environment $W$. The control subsystem processes and compares it with the desired characteristics of the control object, and then makes a new decision, produces the next control effect $U$ based on it. The controlled subsystem also receives information $Y^{\prime}$, processes and compares it with the desired characteristics of the control object and on its basis corrects the error $H^{*}$.

The control system for the process of objects state analysis and forecasting can be represented as a tuple:

$$
S_{\text {con }}=<S, O, Y, Z, W, Q, Y_{a}, D>
$$

where $Z$ is the purpose of control;

$$
D=<I, H, U, Y_{O Y}, Y_{m}, Y^{\prime}, H^{*}, Y_{a d j}^{\prime}>
$$

is the internal environment of the control system $S_{\text {con }}$; $Y=<W, H, H^{*}, Y_{m}>$ is the object model, the result $Y_{m}$ of which is FCM.
Let's write expression (1) for a dynamic system:

$$
\begin{aligned}
& \forall t \in\{1, \ldots, T, \ldots\} S_{t}= \\
& =\left\{\begin{array}{c}
s_{1}^{(t)} F_{1}\left(\varphi_{1,1}\left(s_{1}^{(t-1)}, \ldots, s_{1}^{\left(t-L_{1}^{1}\right)}\right), \varphi_{1, N}\left(s_{N}^{(t-1)}, \ldots, s_{N}^{\left(t-L_{1}^{N}\right)}\right)\right) \times \mathrm{r}_{1}, \\
s_{2}^{(t)} F_{2}\left(\varphi_{2,1}\left(s_{1}^{(t-1)}, \ldots, s_{1}^{\left(t-L_{2}^{1}\right)}\right), \varphi_{2, N}\left(s_{N}^{(t-1)}, \ldots, s_{N}^{\left(t-L_{2}^{N}\right)}\right)\right) \times \mathrm{r}_{2}, \\
\ldots \\
s_{N}^{(t)} F_{N}\left(\varphi_{N, 1}\left(s_{1}^{(t-1)}, \ldots, s_{1}^{\left(t-L_{N}^{1}\right)}\right), \varphi_{N, N}\left(s_{N}^{(t-1)}, \ldots, s_{N}^{\left(t-L_{N}^{N}\right)}\right)\right) \times \mathrm{r}_{N},
\end{array}\right.
\end{aligned}
$$

where $S$ is the multidimensional time series; $S_{t}=\left(s_{1}^{(t)}, s_{2}^{(t)}, \ldots, s_{N}^{(t)}\right)$ is the time sample of the state of the analyzed object presented as a multidimensional time series at the $t$-th time point; $s_{j}^{(t)}$ is the value of the $j$-th component of the multidimensional time series at the $t$-th time point; $L_{j}^{i}$ is the maximum value of the time delay of the $i$-th component relative to the $j$-th one; $\varphi_{i j}$ is the operator for taking into account the interaction between the $i$-th and $j$-th components of the multidimensional time series; $F_{i}$ is the conversion to obtain $s^{(t)}, i=1, \ldots, N$; $N$ is the number of components of the multidimensional time series; $\boldsymbol{\imath}$ is the operator for taking into account the degree of awareness of the object state.

From expression (2), we can conclude that it allows describing the processes in the analyzed object taking into account time delays. Delays are required to collect, process and summarize information and take into account the degree of awareness of the object state. Also, this expression (2) allows describing the processes that have quantitative and qualitative units of measurement and the processes occurring in Fig. 1.

5. 3. Algorithm for implementing the estimation and forecasting method in intelligent decision support systems

The estimation and forecasting method in intelligent decision support systems consists of the following sequence of actions (Fig. 2):

1. Entering initial data. At this stage, available initial data about the analyzed object are entered. The basic model of the object state is initialized.

2. Identifying factors and relationships between them. At this stage, the problem is analyzed, the purpose and objectives of analyzing and forecasting the object state are determined, and cognitive structuring of available information about the object state is carried out.

$$
s_{i(\text { norm })}^{\left(t-l_{i}^{j}\right)}=\frac{s_{i}^{\left(t-l_{i}^{j}\right)}-s_{i(\min )}}{s_{i(\max )}-s_{i(\min )}}, l_{i}^{j}=0, \ldots, L_{i}^{j},
$$

where $s_{i(\text { norm })}^{\left(t-l_{i}^{j}\right)}$ is the normalized value; $s_{i(\max }, s_{i(\min )}$ are the maximum and minimum values, respectively.

As a rule, a set of factors, relationships between them, restrictions imposed on input parameters, as well as their values, are determined on the basis of available information on the results of inquiry from the knowledge base. The need to use data from the knowledge base is due to the lack or incompleteness of input information about the analyzed object. Resources (computational, time and spatial) are considered as constraints imposed on factors.

3. Setting the values of factors and relationships between them. 


\section{1. Processing initial data.}

As the processing of the initial data is a preparatory stage for constructing the FCM, we operate with the «vertex» concept.

The values of vertex parameters $x_{v i}, i=\overline{1, h}$ ( $h$ is the number of factors) can be represented as: numbers that differ in units of measurement and order of magnitude; intervals $x_{v_{i}}=\left[x_{v_{i}}, x_{v_{i}}\right]$, where $x_{v i 1}, x_{v i 2}$ are the minimum and maximum values of vertices; verbal descriptions; fuzzy triangular numbers $x_{v_{i}}=\left[x_{v_{i} 1}, x_{v_{i}}, x_{v_{3}}\right]$, where $x_{v i 1}, x_{v i 2}, x_{v i 3}$ are the minimum, most expected and maximum values of vertices; fuzzy trapezoidal numbers $x_{v_{i}}=\left[x_{v_{i}}, x_{v_{i} 2}, x_{v_{i} 3}, x_{v_{i} 4}\right]$, where $x_{v i 1}$, $x_{v i 2}$ are the pessimistic and optimistic estimates of interval limits, $x_{v, 3}, x_{v, 3}$ is the interval of the most possible estimate.

3. 2. Normalization of vertex parameter values presented as intervals and fuzzy numbers.

To normalize the values of vertex parameters, the following conversion methods are proposed:

1) for intervals $x_{v_{i}}=\left[x_{v_{i}}, x_{v_{i} 2}\right]$ :

$x_{v_{i}}^{\text {norm }}=\left[\frac{x_{v_{i} 1}}{x_{i}^{\max }}, \frac{x_{v_{i} 2}}{x_{i}^{\max }}\right], \quad x_{i}^{* \max }=\max _{l \leq i \leq h^{s}}\left\{x_{v_{i} 2}\right\} ;$

2) for fuzzy triangular numbers $x_{v_{i}}=\left[x_{v_{i} 1}, x_{v_{i}}, x_{v_{i} 3}\right]$ :

$$
x_{v_{i}}^{\text {norm }}=\left[\frac{x_{v_{i} 1}}{x_{i}^{\max }}, \frac{x_{v_{i} 2}}{x_{i}^{\max }}, \frac{x_{v_{3}}}{x_{i}^{\max }}\right], x_{i}^{* * \max }=\max _{l \leq i \leq h^{*}}\left\{x_{v_{i}}\right\} ; \text {; }
$$

3) for fuzzy trapezoidal numbers $x_{v_{i}}=\left[x_{v_{i} 1}, x_{v_{i} 2}, x_{v_{i} 3}, x_{v_{i} 4}\right]$ :

$$
x_{v_{i}}^{\text {norm }}=\left[\frac{x_{v_{i} 1}}{x_{i}^{\max }}, \frac{x_{v_{i} 2}}{x_{i}^{\max }}, \frac{x_{v_{i} 3}}{x_{i}^{\max }}, \frac{x_{v_{i} 4}}{x_{i}^{\max }}\right], x_{i}^{* * * \max }=\max _{l \leq i \leq h^{m *}}\left\{x_{v_{i} 4}\right\} ;
$$

4) for fuzzy polyhedral numbers $x_{v_{i}}=\left[x_{v_{i}}, x_{v_{i}}, x_{v_{i} 3}, x_{v_{i}}\right.$, $\left.\ldots, x_{v_{i} N}\right]$ :

$$
\begin{aligned}
& x_{v_{i}}^{\text {norm }}=\left[\frac{x_{v_{i} 1}}{x_{i}^{\max }}, \frac{x_{v_{i} 2}}{x_{i}^{\max }}, \frac{x_{v_{i}} 3}{x_{i}^{\max }}, \frac{x_{v_{i} 4}}{x_{i}^{\max }}, \ldots, \frac{x_{v_{i} N}}{x_{i}^{\max }}\right], \\
& x_{i}^{N * \max }=\max _{l \leq i \leq h^{N *}}\left\{x_{v_{i} N}\right\} ;
\end{aligned}
$$

where $x_{v_{1}}^{\text {norm }}$ is the normalized values of vertex parameters, $x_{v_{i}}^{n o r m} \in[0,1] ; x_{v i 2}, x_{v i 3}, x_{v i 4}$ is the maximum values of vertex parameters; $x_{i}^{* \max }, x_{i}^{* * \max }, x_{i}^{* * * \max }$ is the maximum values of vertex parameters presented as intervals, fuzzy triangular and trapezoidal numbers $; h^{*}, h^{* *}, h^{* * *}$ is the number of vertices whose parameter values are represented as intervals, fuzzy numbers. As a result of normalization, the values of vertex parameters are intervals with normalized vertex parameter values $x_{v_{i}}^{\text {norm }} \in[0,1]$.

3.3. Normalization of values of relationships between vertices presented as intervals, fuzzy numbers.

To normalize the values of relationships, the following conversion methods are proposed:

1) for intervals $w_{i j}=\left[w_{i j 1}, w_{i j 2}\right]$ :

$$
w_{i j}^{n o r m}=\left[\frac{w_{i j 1}}{w^{\max }}, \frac{w_{i j 2}}{w^{\max }}\right], \quad w^{* \max }=\max _{\substack{l \leq i \leq h \\ l \leq j \leq h}}\left\{w_{i j 2}\right\} ;
$$

2) for fuzzy triangular numbers $w_{i j}=\left[w_{i j 1}, w_{i j 2}, w_{i j 3}\right]$ :

$$
w_{i j}^{n o r m}=\left[\frac{w_{i j 1}}{w^{\max }}, \frac{w_{i j 2}}{w^{\max }}, \frac{w_{i j 3}}{w^{\max }}\right], w^{* * \max }=\max _{\substack{l \leq i \leq h \\ l \leq j \leq h}}\left\{w_{i j 3}\right\} ;
$$

3) for fuzzy trapezoidal numbers:

$$
\begin{aligned}
& w_{i j}^{\text {norm }}=\left[\frac{w_{i j 1}}{w^{\max }}, \frac{w_{i j 2}}{w^{\max }}, \frac{w_{i j 3}}{w^{\max }}, \frac{w_{i j 4}}{w^{\max }}\right], \\
& w^{* * * \max }=\max _{\substack{l \leq i \leq h \\
l \leq j \leq h}}\left\{w_{i j 4}\right\} ;
\end{aligned}
$$

4) for fuzzy polyhedral numbers:

$$
\begin{aligned}
& w_{i j}^{\text {norm }}=\left[\frac{w_{i j 1}}{w^{\max }}, \frac{w_{i j 2}}{w^{\max }}, \frac{w_{i j 3}}{w^{\max }}, \frac{w_{i j 4}}{w^{\max }}, \ldots, \frac{w_{i j N}}{w^{\max }}\right], \\
& w^{N * \max }=\max _{\substack{l \leq i \leq h, l \leq j \leq h}}\left\{w_{i j N}\right\} ;
\end{aligned}
$$

where $w_{i j}^{\text {norm }}$ is the normalized interval values of relationships between vertices $v_{i}$ and $v_{j} w_{i j}^{n o r m} \in[-1,1] ; w^{*} \max , w^{* *} \max$, $w^{* * * * m a x}$ are the maximum values of relationships represented as intervals and fuzzy numbers. As a result of normalization, the values of relationships between the vertices are intervals with the normalized values of relationships.

3. 4. Structuring the values of relationships between vertices.

To determine causal relationships, a scale is defined to assess the nature and strength of relationships between the vertices. The structuring is performed as follows: each value of the relationship, presented as a verbal description, corresponds to one number from the interval $[1,1]$.

The normalization and structuring of the values of relationships between the vertices are necessary to ensure that all the values of relationships belong to the interval $[1,1]$.

4. FCM construction.

Structure formation (preliminary structural adjustment).

FCM consist in establishing structural relationships (in the form of time lags) between the FCM concepts, weighted by the fuzzy values $w_{i j}^{\left(t-l_{i}^{l}\right)}$ of their influence on each other. In this work, modified ANFIS-type models (Adaptive NeuroFuzzy Inference System) are proposed as the FCM $F S_{i}$ that implement fuzzy temporal transformations $F_{i}$. FCM provide the formation, storage and output of the predicted fuzzy values of the respective components of the multidimensional time series with the necessary time delays for FCM.

The input temporal fuzzy variables of the $F S_{i}$ model of the $C_{i}$ concept are related to the output temporal fuzzy variables of those concepts that have a direct impact on the $C_{i}$ concept. The input temporal fuzzy variables $C_{i}$ are pre-weighed by the corresponding fuzzy degrees of influence $w_{i j}^{\left(t-l_{i}^{j}\right)}$ in accordance with expressions (8)-(11), on the basis of which the following transformation is performed:

$$
\tilde{s}_{j}^{\prime\left(t-l_{i}^{j}\right)}=\left(w w_{i j}^{\left(t-l_{i}^{j}\right)} T \tilde{s}_{j}^{\left(t-l_{i}^{j}\right)}\right), \quad l_{i}^{j}=0, \ldots, L_{i}^{j},
$$

where $T$ is the $T$-norm operation.

The original temporal fuzzy variables of the $F S_{i}$ model of the $C_{i}$ concept are intended for the formation, storage and output of predicted values of the $i$-th component of the multidimensional time series corresponding to time lags. Both a priori information about the components of the multidimensional time series available in the knowledge base and estimation or measurement data can be used to construct fuzzy component temporal models $F S_{i}$.

In the first case, it is assumed that the problem of completeness and consistency of the base of fuzzy rules of the $F S_{i}$ model is solved in advance. 


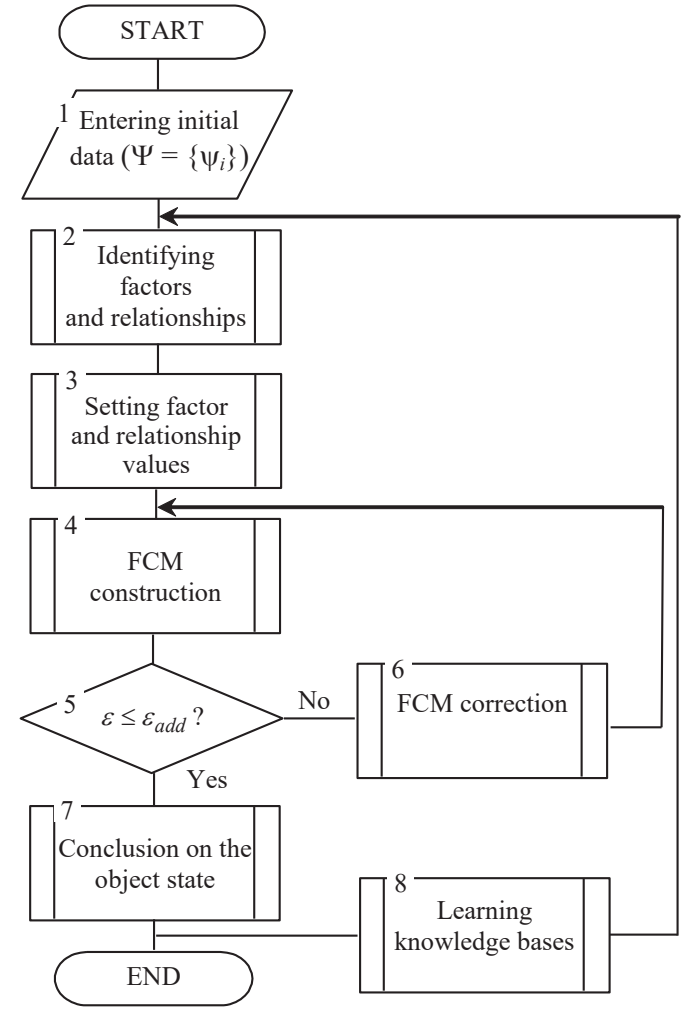

Fig. 2. Algorithm for implementing the method for analyzing and forecasting the object state

If only experimental data are known, then the problem of model identification is set. In practice, there is often a mixed case when the initial base of the model rules is built on the basis of heuristic assumptions and its parameter adjustment (learning) is performed on the basis of a training sample (Fig. 3).

Input temporal fuzzy variables of the $F S_{i}$ model are

$$
S_{1}^{\prime}=\left\{\tilde{s}_{3}^{(t-1)}, \tilde{s}_{3}^{\prime(t-3)}, \tilde{s}_{4}^{(t-3)}, \tilde{s}_{5}^{\prime(t-3)}, \tilde{s}_{1}^{\prime(t-3)}\right\},
$$

and its original fuzzy temporal variables are

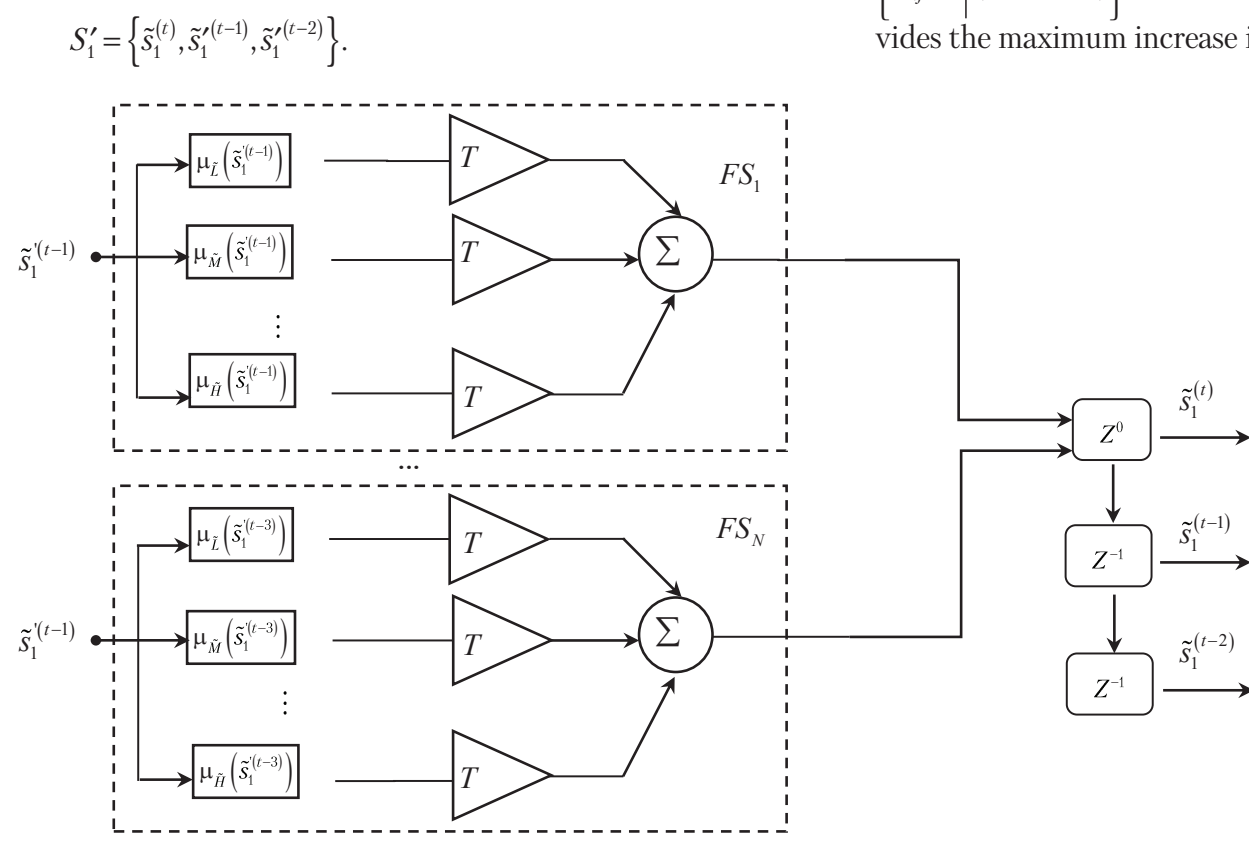

Fig. 3. Structure of the fuzzy component temporal model $F S_{1}$
While constructing the model, truth measures are determined first for the current values of input variables with respect to the correspondence of these fuzzy statements to the prerequisites of all the model rules. After that, aggregation of the truth degrees of the rules prerequisites based on the $T$-norm operation is performed:

$$
\begin{aligned}
& \alpha_{p}=\min \mu_{\tilde{L}}\left(\tilde{s}_{1}^{\prime(t-1)}\right), \mu_{\tilde{L}}\left(\tilde{s}_{3}^{\prime(t-3)}\right), \\
& \mu_{\tilde{M}}\left(\tilde{s}_{4}^{\prime(t-3)}\right), \mu_{\tilde{M}}\left(\tilde{s}_{5}^{\prime(t-3)}\right), \mu_{\tilde{H}}\left(\tilde{s}_{1}^{(t-3)}\right) .
\end{aligned}
$$

Then, the conclusion of the relevant rules is activated in accordance with the truth degrees of their prerequisites based on the operation of implication (here, Mamdani implications are min-activation operations):

$$
\mu_{\tilde{M}}\left(\tilde{s}_{1}^{(t)}\right)=\min \left(\alpha_{p}, \tilde{M}\right)
$$

Further, the max-disjunction operation is performed, accumulating activated conclusions of all model rules:

$$
\tilde{s}_{1}^{(t)}=\max \left(\mu_{\tilde{M}}\left(\tilde{s}_{1}^{(t)}\right), \ldots, \mu_{\tilde{M}}\left(\tilde{s}_{1}^{(t)}\right), \ldots, \mu_{\tilde{H}}\left(\tilde{s}_{1}^{(t)}\right)\right) .
$$

Next, the normalization, storage and output of fuzzy values of the output variables of the model with the necessary time delays for FCM are performed:

$$
\tilde{s}_{1(\text { norm })}^{(t)}=Z^{0}\left(\tilde{s}_{1}^{(t-1)}\right), \tilde{s}_{1(\text { norm })}^{(t-2)}=Z^{-1}\left(\tilde{s}_{1}^{(t-1)}\right) .
$$

\section{ANN training.}

In this procedure, the ANN is trained using the evolving ANN learning method developed by the authors in [2]. The difference of this method from the known ones is that it allows training not only synaptic weights, but also parameters of the membership function together with the ANN architecture. Also, at this stage, all fuzzy component temporal models FCM are coordinated. Coordination of all fuzzy component temporal models $F S_{i}, i=1, \ldots, N \mathrm{FCM}$ is carried out after their «personalized» parameter adjustment. Coordination is such a change in the modal values and fuzzy degrees of influence $\left\{w_{i j}^{\left(t-l_{i}^{j}\right)} \mid l_{i}^{j}=0, \ldots, L_{i}^{j}\right\}$ between the FCM concepts, which provides the maximum increase in the accuracy of forecasting each of the components of the multidimensional time series without deterioration. The procedure of coordinating fuzzy component temporal models FCM is preceded by the formation of an additional «coordinating» training sample, consisting of retrospective data simultaneously for all components of the multidimensional time series. The procedure for coordinating all fuzzy component temporal models FCM is considered successfully completed if the final error for each of these models does not exceed some threshold. For well-coordinated components of the multidimensional time series or for these models, the Edgeworth-Pareto principle will be used. 
6. Forecasting the state of the analyzed object.

Multidimensional analysis and forecasting of the state of a complex system/process is performed on the basis of structurally and parametrically configured FCM and can be performed in the following modes:

- firstly, direct multidimensional forecasting of the state of a complex system/process for the $t$-th moment of time, i. e. calculation of the values of the output variables of the models $F S_{i}, i=1, \ldots, N$ by the given each time corresponding sets of values of the input variables of these models;

- secondly, self-development and predictive assessment of changes in the state of a complex system/process, in which modeling of the dynamics of state changes is carried out from a situation given by the initial values of all FCM concepts, in the absence of external influences;

- thirdly, development and predictive assessment of changes in the state of a complex system/process, in which modeling of the dynamics of state changes is carried out in a given situation. The situation is given by the initial knowledge of all FCM concepts with external influence on the values of concepts and/or on the relationships of influence between the FCM concepts.

\section{Discussion of the results of the development of the} estimation and forecasting method in intelligent DSS

The estimation and forecasting method in intelligent decision support systems is proposed. To assess the effectiveness of the developed method for evaluating information and analytical support of strategic management, its comparative evaluation with the most popular software products for enterprise management (strategic management) was performed:

- ARIS Business Performance Edition (IDS Scheer AG, Germany);

- IBM WebSphere Business Modeler (IBM, USA);

- System21 Aurora (Campbell Lee Computer Services Limited, Great Britain);

- SAP Strategic Enterprise Management (SAP, Germany);

- Hyperion Performance Scorecard (Oracle, USA);

- CA ERWin Process Modeler (CA, USA).

For a comparative assessment, the actual state of the company was estimated. Everest Limited LLC (Kyiv, Ukraine) was used as the object of the research.

The results of assessing the actual state of the company are given in Table 1, which presents normalized evaluation results.

From the analysis of the data presented in Table 1, it is seen that the presented method has a smaller number of calculations compared to the known estimation and forecasting approaches. The advantage of this method compared to the known ones is lower computational complexity, which in turn increases the efficiency of decision-making regarding the management object.

Tables 2, 3 present comparative results of evaluation of learning efficiency of evolving artificial neural networks.

Before learning, the signs of observations were normalized at the interval [0,1].

It is worth noting that the proposed training procedure showed a better PC (partition coefficient) result compared to EFCM and a better operating time result compared to FCM. The research showed that this training procedure provides on average $10-18 \%$ higher learning efficiency of artificial neural networks and does not accumulate training errors (Tables 2, 3).
Table 1

Comparison of computational complexity of the software and the developed method for assessing the real state of the company

\begin{tabular}{|c|l|c|c|}
\hline No. & \multicolumn{1}{|c|}{ Software } & $\begin{array}{c}\text { Number } \\
\text { of calcu- } \\
\text { lations }\end{array}$ & $\begin{array}{c}\text { Developed } \\
\text { method (by } \\
\text { the number of } \\
\text { calculations) }\end{array}$ \\
\hline 1 & $\begin{array}{l}\text { ARIS Business Performance Edi- } \\
\text { tion (IDS Scheer AG) }\end{array}$ & 67,000 & 58,960 \\
\hline 2 & $\begin{array}{l}\text { IBM WebSphere Business Mode- } \\
\text { ler (IBM) }\end{array}$ & 64,500 & 58,760 \\
\hline 3 & $\begin{array}{l}\text { System21 Aurora (Campbell Lee } \\
\text { Computer Services Limited) }\end{array}$ & 57,000 & 48,450 \\
\hline 4 & $\begin{array}{l}\text { SAP Strategic Enterprise Mana- } \\
\text { gement (SAP) }\end{array}$ & 39,830 & 35,847 \\
\hline 5 & $\begin{array}{l}\text { Hyperion Performance Scorecard } \\
\text { (Oracle) }\end{array}$ & 46,200 & 40,194 \\
\hline 6 & CA ERWin Process Modeler (CA) & 43,050 & 37,023 \\
\hline
\end{tabular}

Table 2

Comparative results of evaluation of learning efficiency of evolving artificial neural networks

\begin{tabular}{|l|c|c|c|}
\hline \multicolumn{1}{|c|}{ System } & $\begin{array}{c}\text { Algorithm } \\
\text { parameters }\end{array}$ & $\begin{array}{c}\text { XB (Xie-Beni } \\
\text { index) }\end{array}$ & $\begin{array}{c}\text { Time, } \\
\text { sec }\end{array}$ \\
\hline FCM (Fuzzy C-Means) & - & 0.1903 & 2.69 \\
\hline EFCM & Dthr $=0.24$ & 0.1136 & 0.14 \\
\hline EFCM & Dthr $=0.19$ & 0.1548 & 0.19 \\
\hline $\begin{array}{l}\text { Proposed system (batch } \\
\text { mode) }\end{array}$ & delta $=0.1$ & 0.0978 & 0.37 \\
\hline $\begin{array}{l}\text { Proposed system (online } \\
\text { mode) }\end{array}$ & delta $=0.1$ & 0.1127 & 0.25 \\
\hline
\end{tabular}

Comparative results of clustering

Table 3

\begin{tabular}{|l|c|c|c|}
\hline \multicolumn{1}{|c|}{ System } & $\begin{array}{c}\text { Algorithm } \\
\text { parameters }\end{array}$ & $\begin{array}{c}\text { XB (Xie-Beni } \\
\text { index) }\end{array}$ & $\begin{array}{c}\text { Time, } \\
\text { sec }\end{array}$ \\
\hline FCM (Fuzzy C-Means) & Dthr $=0.6$ & 0.2963 & 0.81 \\
\hline EFCM & Dthr $=0.6$ & 0.2330 & 0.54 \\
\hline $\begin{array}{l}\text { Proposed system (batch } \\
\text { mode) }\end{array}$ & delta $=0.4$ & 0.2078 & 0.45 \\
\hline $\begin{array}{l}\text { Proposed system (online } \\
\text { mode) }\end{array}$ & delta $=0.4$ & 0.2200 & 0.30 \\
\hline
\end{tabular}

These results can be seen from the results in the last terms of Table 2 and Table 3 as the difference of the Xie-Beni index.

The main advantages of the proposed evaluation method are:

- flexible hierarchical structure of indicators, which allows reducing the problem of multi-criteria evaluation of alternatives to one criterion or using a vector of indicators for selection;

- unambiguity of the object state estimate;

- wide scope of use (decision support systems);

- simplicity of mathematical calculations;

- no accumulation of learning errors;

- adaptability of the system of indicators in the course of work;

- learning not only the synaptic weights of the artificial neural network, but also the type and parameters of the membership function; 
- learning the architecture of artificial neural networks;

- calculation of data for one epoch without the need to store previous calculations;

- ability to synthesize the optimal structure of the decision support system.

The disadvantages of the proposed method include:

- loss of informativeness in assessing the state of the support object by building a membership function. This loss of informativeness can be reduced by choosing the type of membership function in the practical implementation of the proposed method in decision support systems. The choice of the type of membership function depends on computing resources of a particular electronic computing device;

- lower accuracy of estimation based on a separate estimation parameter of the object state;

- lower accuracy of estimation compared to other estimation methods.

This method allows:

- assessing the object state;

- identifying effective measures to improve management efficiency;

- increasing the speed of object state estimation;

- reducing the use of computing resources of decision support systems.

According to the results of the effectiveness analysis of the proposed method, it is seen that its computational complexity is $15-25 \%$ less, compared to the methods for assessing the effectiveness of decisions presented in Table 1.

This study is a further development of research aimed at developing methodological principles for improving the efficiency of information and analytical support, published earlier [2, 4-6]. Further research should be aimed at reducing computational costs when processing various data in special-purpose systems.

\section{Conclusions}

1. A formalized description of the problem of object state analysis and forecasting in intelligent decision support systems is carried out. This formalization allows describing processes that take place in intelligent decision support systems when solving problems of analyzing and forecasting the object state. The efficiency of the process of object state analysis and forecasting is chosen as an efficiency criterion for the method.
2. In the course of the research, the estimation and forecasting method in intelligent decision support systems is developed. It allows:

- conducting multidimensional analysis and forecasting of the objects state under uncertainty;

- provides a predictive estimate under non-stochastic uncertainty, nonlinearity of mutual influence, partial inconsistency and significant interdependence of components of a multidimensional time series;

- training artificial neural networks for intelligent decision support systems.

3. The use of the proposed method on the example of assessing and forecasting the state of the enterprise is given. This example showed an increase in data processing efficiency at the level of 15-25\% using additional advanced procedures.

\section{Acknowledgments}

The author's team expresses gratitude for the assistance in preparing the paper to:

- Doctor of Technical Sciences, Professor Oleksiy Kuvshinov, Deputy Head of the Educational and Scientific Institute of the Ivan Chernyakhovsky National Defense University of Ukraine.

- Doctor of Technical Sciences, Senior Researcher Sova Oleg, Head of the Department of Automated Control Systems of the Military Institute of Telecommunications and Information Technologies named after Heroes of Kruty.

- Doctor of Technical Sciences, Senior Researcher Zhuravskiy Yuriy, Head of the Department of Electrical Engineering and Electronics of the Zhytomyr Military Institute named after S.P. Korolyov.

- Honored Worker of Science and Technology of Ukraine, Doctor of Technical Sciences, Professor Slyusar Vadym, Chief Researcher of the Central Research Institute of Armaments and Military Equipment of the Armed Forces of Ukraine.

- Doctor of Technical Sciences, Professor Rothstein Oleksandr, Professor of the Mahon Lev Jerusalem Polytechnic Institute.

- Candidate of Technical Sciences, Associate Professor Oleksandr Bashkirov, Leading Researcher at the Central Research Institute of Armaments and Military Equipment of the Armed Forces of Ukraine.

\section{References}

1. Bashkyrov, O. M., Kostyna, O. M., Shyshatskyi, A. V. (2015). Rozvytok intehrovanykh system zviazku ta peredachi danykh dlia potreb Zbroinykh Syl. Ozbroiennia ta viyskova tekhnika, 1, 35-39.

2. Dudnyk, V., Sinenko, Y., Matsyk, M., Demchenko, Y., Zhyvotovskyi, R., Repilo, I. et. al. (2020). Development of a method for training artificial neural networks for intelligent decision support systems. Eastern-European Journal of Enterprise Technologies, 3 (2 (105)), 37-47. doi: https://doi.org/10.15587/1729-4061.2020.203301

3. Bodyanskiy, E., Strukov, V., Uzlov, D. (2017). Generalized metrics in the problem of analysis of multidimensional data with different scales. Zbirnyk naukovykh prats Kharkivskoho universytetu Povitrianykh Syl, 3, 98-101.

4. Pievtsov, H., Turinskyi, O., Zhyvotovskyi, R., Sova, O., Zvieriev, O., Lanetskii, B., Shyshatskyi, A. (2020). Development of an advanced method of finding solutions for neuro-fuzzy expert systems of analysis of the radioelectronic situation. EUREKA: Physics and Engineering, 4, 78-89. doi: https://doi.org/10.21303/2461-4262.2020.001353

5. Zuiev, P., Zhyvotovskyi, R., Zvieriev, O., Hatsenko, S., Kuprii, V., Nakonechnyi, O. et. al. (2020). Development of complex methodology of processing heterogeneous data in intelligent decision support systems. Eastern-European Journal of Enterprise Technologies, 4 (9 (106)), 14-23. doi: https://doi.org/10.15587/1729-4061.2020.208554 
6. Shyshatskyi, A. (2020). Complex Methods of Processing Different Data in Intellectual Systems for Decision Support System. International Journal of Advanced Trends in Computer Science and Engineering, 9 (4), 5583-5590. doi: https://doi.org/10.30534/ ijatcse/2020/206942020

7. Trotsenko, R. V., Bolotov, M. V. (2014). Data extraction process for heterogeneous sources. Privolzhskiy nauchniy vestnik, $12-1(40), 52-54$.

8. Rotshteyn, A. P. (1999). Intellektual'nye tehnologii identifikatsii: nechetkie mnozhestva, neyronnye seti, geneticheskie algoritmy. Vinnitsa: «UNIVERSUM», 295.

9. Alpeeva, E. A., Volkova, I. I. (2019). The use of fuzzy cognitive maps in the development of an experimental model of automation of production accounting of material flows. Russian Journal of Industrial Economics, 12 (1), 97-106. doi: https://doi.org/ 10.17073/2072-1633-2019-1-97-106

10. Zagranovskaya, A. V., Eissner, Y. N. (2017). Simulation scenarios of the economic situation based on fuzzy cognitive maps. Modern Economics: Problems and Solutions, 10 (94), 33-47. doi: https://doi.org/10.17308/meps.2017.10/1754

11. Simankov, V. S., Putyato, M. M. (2013). Issledovanie metodov kognitivnogo analiza. Perspektivy razvitiya informatsionnyh tehnologiy, 13, 31-35.

12. Onykiy, B., Artamonov, A., Ananieva, A., Tretyakov, E., Pronicheva, L., Ionkina, K., Suslina, A. (2016). Agent Technologies for Polythematic Organizations Information-Analytical Support. Procedia Computer Science, 88, 336-340. doi: https://doi.org/10.1016/ j.procs.2016.07.445

13. Ko, Y.-C., Fujita, H. (2019). An evidential analytics for buried information in big data samples: Case study of semiconductor manufacturing. Information Sciences, 486, 190-203. doi: https://doi.org/10.1016/j.ins.2019.01.079

14. Çavdar, A. B., Ferhatosmanoğlu, N. (2018). Airline customer lifetime value estimation using data analytics supported by social network information. Journal of Air Transport Management, 67, 19-33. doi: https://doi.org/10.1016/j.jairtraman.2017.10.007

15. Ballester-Caudet, A., Campíns-Falcó, P., Pérez, B., Sancho, R., Lorente, M., Sastre, G., González, C. (2019). A new tool for evaluating and/or selecting analytical methods: Summarizing the information in a hexagon. TrAC Trends in Analytical Chemistry, 118, 538-547. doi: https://doi.org/10.1016/j.trac.2019.06.015

16. Ramaji, I. J., Memari, A. M. (2018). Interpretation of structural analytical models from the coordination view in building information models. Automation in Construction, 90, 117-133. doi: https://doi.org/10.1016/j.autcon.2018.02.025

17. Pérez-González, C. J., Colebrook, M., Roda-García, J. L., Rosa-Remedios, C. B. (2019). Developing a data analytics platform to support decision making in emergency and security management. Expert Systems with Applications, 120, 167-184. doi: https:// doi.org/10.1016/j.eswa.2018.11.023

18. Chen, H. (2018). Evaluation of Personalized Service Level for Library Information Management Based on Fuzzy Analytic Hierarchy Process. Procedia Computer Science, 131, 952-958. doi: https://doi.org/10.1016/j.procs.2018.04.233

19. Chan, H. K., Sun, X., Chung, S.-H. (2019). When should fuzzy analytic hierarchy process be used instead of analytic hierarchy process? Decision Support Systems, 125, 113114. doi: https://doi.org/10.1016/j.dss.2019.113114

20. Osman, A. M. S. (2019). A novel big data analytics framework for smart cities. Future Generation Computer Systems, 91, 620-633 doi: https://doi.org/10.1016/j.future.2018.06.046

21. Gödri, I., Kardos, C., Pfeiffer, A., Váncza, J. (2019). Data analytics-based decision support workflow for high-mix low-volume production systems. CIRP Annals, 68 (1), 471-474. doi: https://doi.org/10.1016/j.cirp.2019.04.001

22. Harding, J. L. (2013). Data quality in the integration and analysis of data from multiple sources: some research challenges. ISPRS - International Archives of the Photogrammetry, Remote Sensing and Spatial Information Sciences, XL-2/W1, 59-63. doi: https://doi.org/10.5194/isprsarchives-xl-2-w1-59-2013

23. Rybak, V. A., Ahmad, S. (2016). Analysis and comparison of existing decision support technology. Sistemniy analiz i prikladnaya informatika, 3, 12-18.

24. Rodionov, M. A. (2014). Problems of information and analytical support of contemporary strategic management. Civil Aviation High Technologies, 202, 65-69. Available at: https://avia.mstuca.ru/jour/article/view/153/79

25. Bednáŕ, Z. (2018). Information Support of Human Resources Management in Sector of Defense. Vojenské rozhledy, 27 (1), $45-68$.

26. Palchuk, V. (2017). Methods of Content-Monitoring and Content-Analysis of Information Flows: Modern Features. Academic Papers of the Vernadsky National Library of Ukraine, 48, 506-526. doi: https://doi.org/10.15407/np.48.506

27. Mir, S. A., Padma, T. (2016). Evaluation and prioritization of rice production practices and constraints under temperate climatic conditions using Fuzzy Analytical Hierarchy Process (FAHP). Spanish Journal of Agricultural Research, 14 (4), e0909. doi: https:// doi.org/10.5424/sjar/2016144-8699

28. Kljushin, V. V. (2014). Theoretical and methodological basis for the formation and evaluation of the level of the economic system's strategic economic potential. Modern Management Technology, 12 (48). Available at: https://sovman.ru/article/4805/

29. Bogomolova, I. P., Omel'chenko, O. M. (2014). Analysis of influence factors of economic efficiency on the economy of the integrated structures. Proceedings of the Voronezh State University of Engineering Technologies, 3, 157-162.

30. Sherafat, A., Yavari, K., Davoodi, S. M. R. (2014). Evaluation of the Strategy Management Implementation in Project-Oriented Service Organizations. Acta Universitatis Danubius, 10 (1), 16-25. Available at: http://journals.univ-danubius.ro/index.php/ oeconomica/article/view/2020/2053 